\title{
$N$-Benzyloxycarbonyl-2-phenylaminooxazolidine as a Selective Amine Benzyloxycarbonylating Reagent
}

\author{
Chi Sung Song, Jae Nyoung Kim, ${ }^{\dagger}$ and Taek Hyeon Kim \\ Department of Applied Chemistry, Chonnam National University, Gwangju 500-757, Korea. *E-mail: thkim@chonnam.ac.kr \\ ${ }^{\dagger}$ Department of Chemistry and Institute of Basic Science, Chonnam National University, Gwangju 500-757, Korea \\ Received March 10, 2005
}

Key Words : Chemoselective benzyloxycarbonylation, $N$-Benzyloxycarbonyl-2-phenyliminooxazolidine, Diamine

The chemoselective benzyloxycarbonylation of amines is one of the most basic reactions in synthetic organic chemistry. ${ }^{1}$ A variety of N-benzyloxycarbonyl transfer reagents have been developed by devising appropriate leaving groups, e.g., chloride, ${ }^{2}$ imidazole,${ }^{3}$ imide, ${ }^{4}$ oxime,${ }^{5}$ enolate, ${ }^{6}$ and $N$-sulfonylanilide. ${ }^{7}$ Each of these methods has its advantages and disadvantages in any given situation, particularly in terms of selectivity, and more selective reagents are required. Recently we described the preparation of 2-phenylamino-2-oxazoline 2 from the cyclization of $\mathrm{N}$ (2-hydroxyethyl)- $N$ '-phenylthiourea. ${ }^{8}$ The 2-phenylamino-2oxazoline heterocyclic is viewed as a good leaving group for the chemoselective acylation of amines due to a bulky and electron-acceptable reagent. ${ }^{9}$ Here we report that $N$ benzyloxycarbonyl-2-phenyliminooxazolidine $\mathbf{2}$ serves as a neutral reagent for the chemoselective benzyloxycarbonylation of primary amines in the presence of secondary amine or alcohol, and for the benzyloxycarbonylation of less sterically hindered amine in two different primary amines.

The synthesis of 2-phenylamino-2-oxazoline was readily performed by reacting 1,2-aminoalcohol with phenyl isothiocyanate to yield the corresponding $N$-(2-hydroxyethyl)$N^{\prime}$-methylthiourea, followed by the cyclo-desulfurization of the thiourea to the 2-phenylamino-2-oxazoline in good yield in a one-pot reaction using $p$-toluenesulfonyl chloride and $\mathrm{NaOH}$, as we described previously (Scheme 1). ${ }^{8 \mathrm{a}}$ Acylation of the 2-phenylamino-2-oxazoline can conceivably proceed through an attack of the acyl halide either by the exonitrogen to provide $N$-acylated-2-phenyllaminooxazolines or by the endo-nitrogen to give $N$-acylated 2-phenyliminoxazolidine. ${ }^{9}$ Benzyloxycarbonylation of the 2-phenylamino2-oxazoline 1 with benzyloxycarbony chloride $(\mathrm{CbzCl})$ under $n$-BuLi yielded only the endo-nitrogen product (Scheme 1). Column chromatography yielded $\mathbf{2}$ an air stable solid at a yield of $c a .76 \%$.

We next examined $N$-benzyloxycarbonyl transfer by 2 to various amines, namely, benzylamine, $\alpha$-methylbenzylamine, $\alpha, \alpha$-dimethylbenzylamine, and $N$-methylbenzylamine. Benzyloxycarbonylation of amines by $\mathbf{2}$ was initially examined in a variety of solvents such as $\mathrm{THF}, \mathrm{CCl}_{4}$, or toluene. No reaction occurred in THF or $\mathrm{CCl}_{4}$ under reflux for $40 \mathrm{~h}$. However, in toluene under reflux, primary and secondary amines were converted to their corresponding carbamates. Results are summarized in Table 1, which also shows that reaction times were dependent on bulkiness of amine groups, and in particular, primary amines were more reactive than secondary amines (entries 1-2). This observed reactivity difference is attributed to the different steric effect of primary and secondary amines with respect to the aminolysis of esters. ${ }^{10}$ The hindered primary amines, $\alpha$ methylbenzylamine and $\alpha, \alpha$-dimethylbenzylamine required longer reaction time than the less hindered primary amine benzylamine (entries 1, 3-4). Only $18 \%$ of the highly sterically hindered $\alpha, \alpha$-dimethylbenzylamine under toluene

Table 1. $N$-Benzyloxycarbonylation of various amines using 2

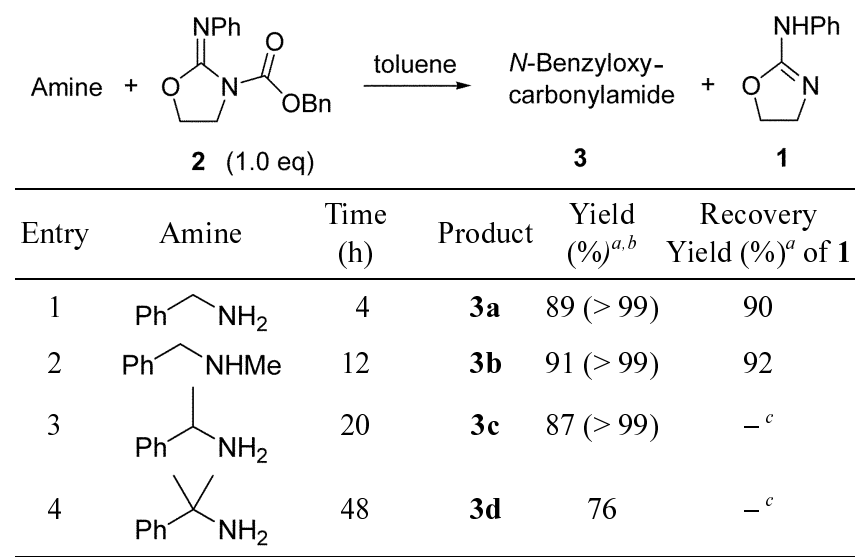

${ }^{a}$ Isolated yield. ${ }^{b}$ Yields in parenthesis are determined by ${ }^{1} \mathrm{H}$ NMR. ${ }^{c}$ Not isolated

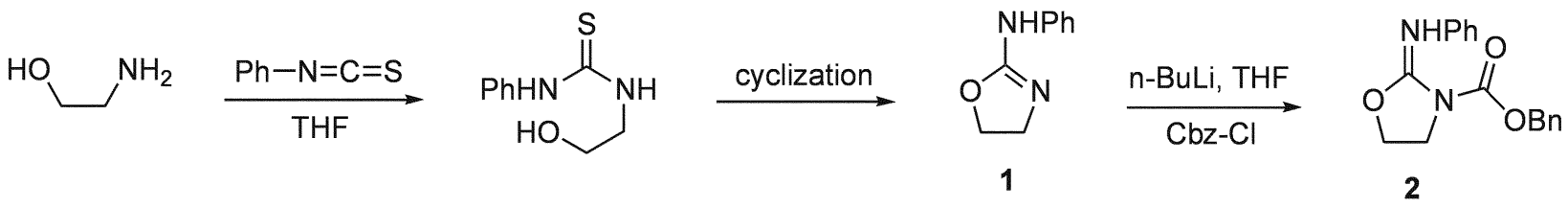

Scheme 1 
Table 2. Chemoselective acetylation of diamines using 2

Entry Time (h)

${ }^{a}$ Yield by flash column chromatography. ${ }^{b}$ Yields in parenthesis are determined by ${ }^{1} \mathrm{H}$ NMR

reflux was converted to the Cbz-derivative. Thus, the reaction rate was found to be markedly affected by the steric bulks of the starting amines and the acylating reagent 2 . Moreover, the leaving group, 2-phenylaminooxazoline $\mathbf{1}$ was recovered almost quantitatively for recycling, simply by extracting the organic layer with acidified aqueous solution. After washing the organic layer, evaporation yielded the crude benzyloxycarbonylated product, which was further purified by column chromatography or recrystallization.

The observed substantial difference in the reaction rates of hindered and less hindered amines prompted us to examine the use of $\mathrm{N}$-benzyloxycarbonyl-2-phenyliminooxazolidine 2 for the selective benzyloxycarbonylation of diamines, namely, $N$-propylethylene diamine, $N$-benzylethylene diamine, and 2-methylpiperizine. These benzyloxycarbonylations furnished the required mono-Cbz-derivatives in good yields, i.e., benzyloxycarbonylated products were produced at less hindered nitrogen (Table 2, entries 1-3). However acylation of these amines using $\mathrm{CbzCl}$ afforded predominantly diacylated products. Moreover, 2-aminoethanol containing both amino and hydroxyl group were selectively converted into the desired amides in high yields in the presence of the hydroxyl group (Table 2, entry 4). The reaction products obtained in each case were compared with authentic samples of the appropriate carbamate products by NMR spectroscopy. ${ }^{11-13}$

In conclusion, $N$-benzyloxycarbonylated 2-phenylaminooxazolidine was found to selectively benzyloxycarbonylate amines. We believe that this novel benzyloxycarbonylating agent can be widely used for the selective protection of various polyamines. Its further development as a general acylating agent is in progress.

\section{Experimental Section}

General. Reagent grade chemicals were purchased from Aldrich Co., and all solvents were reagent grade. Toluene was distilled from calcium hydride. ${ }^{1} \mathrm{H}$ NMR spectra were recorded on a $300 \mathrm{MHz}$ spectrometer, and quoted chemical shifts are in ppm using TMS as an internal standard. IR spectra were recorded on a Nicolet FT IR spectrometer.

Synthesis of $\boldsymbol{N}$-benzyloxycarbonyl-2-phenyliminooxazolidine 2. To a stirred solution of $1(0.5 \mathrm{~g}, 3.3 \mathrm{mmol})$ in dry THF $(20 \mathrm{~mL})$ under nitrogen at $0{ }^{\circ} \mathrm{C}$ was added a solution of $n$-BuLi $(0.52 \mathrm{~mL}, 4.0 \mathrm{mmol}, 1.6 \mathrm{M}$ solution in $\mathrm{THF})$ dropwise with a syringe. After $30 \mathrm{~min} \mathrm{CbzCl}(0.3 \mathrm{~mL}$, $4.0 \mathrm{mmol}$ ) was added and the reaction mixture was then stirred for $45 \mathrm{~min}$ at $0{ }^{\circ} \mathrm{C}$, quenched with saturated $\mathrm{NH}_{4} \mathrm{Cl}$ solution $(20 \mathrm{~mL})$, and extracted with ether $(30 \mathrm{~mL} \times 3)$. The organic layer was dried, filtered, and concentrated to give the crude product, which was then purified by flash column chromatography to give the cyclized product 2 . White solid, $77 \%$ yield; $\mathrm{mp} 89{ }^{\circ} \mathrm{C} ; R_{f}=0.4$ (ethyl acetate/hexane $1 / 1$ ); ${ }^{1} \mathrm{H}$ NMR (300 MHz, $\mathrm{CDCl}_{3}$ ) 7.49-7.25 (m, 7H, Ar), 7.07-7.00 (m, 3H, Ar), 5.31 (s, 2H, $\left.\mathrm{OCH}_{2} \mathrm{Ar}\right), 4.28\left(\mathrm{t}, 2 \mathrm{H}, \mathrm{OCH}_{2}, J=\right.$ $8.4 \mathrm{~Hz}), 4.00$ (t, $\left.2 \mathrm{H}, \mathrm{NCH}_{2}, J=8.4 \mathrm{~Hz}\right) ;{ }^{13} \mathrm{C} \mathrm{NMR}(75 \mathrm{MHz}$, $\left.\mathrm{CDCl}_{3}\right)$ 150.8, 146.3, 145.7, 135.4, 128.6, 128.6, 128.4, 128.3, 123.7, 122.8, 68.2, 60.75, 64.0, 44.5; EIMS m/e 296 (M, 6.7), 91 (100).

Typical procedure used for the chemoselective $\mathrm{N}$ benzyloxycarbonylation of various amines. The iminooxazolidine $2(0.1 \mathrm{~g}, 0.34 \mathrm{mmol})$ was added to a stirred solution of $N$-propylethylenediamine $(41.6 \mu \mathrm{L}, 0.34 \mathrm{mmol})$ in dry toluene $(10 \mathrm{~mL})$ in a nitrogen atmosphere at room temperature. The reaction mixture was then stirred for $8 \mathrm{~h}$ under reflux and concentrated to dryness using a rotary evaporator. The residue was then purified using a silica gel column (ethyl acetate/methanol $2 / 3, R_{f}=0.3$ ) to give $N$ benzyl- $N$-benyloxycarbonylethylenediamine (63 mg, 79\%) as yellowish oil and the recovered phenylaminooxazoline 1 (48 mg, 87\%). The physical data of 3 were comparable to those previous reported. ${ }^{11-13}$

Acknowledgment. This work was supported by the Basic 
Research Program of the Korean Science and Engineering Foundation (Grant No. R05-2004-000-11207-0) and the Regional Technology Innovation Program of the Ministry of Commerce, Industry and Energy (grant No. RTI04-03-03).

\section{References}

1. Greene, T. W.; Wuts, P. G. M. Protective Group in Organic Synthesis; John Willey and Sons, Inc.: New York, 1991; p 503.

2. Atwell, G. J.; Denny, W. A. Synthesis 1984, 1032.

3. Sharma, S. K.; Miller, M. J.; Payne, S. M. J. Med. Chem. 1989, $32,357$.

4. Henklein, P.; Heyne, H.-U.; Halatsch, W.-R.; Niedrich, H. Synthesis 1987, 166.

5. Itoh, M.; Hagiwara, D.; Kamiya, T. Bull. Chem. Soc. Jpn. 1977, $50,718$.

6. Kita, Y.; Haruta, J.; Yasuda, H.; Fujunaga, K.; Shirouchi, Y.; Tamura, Y. J. Org. Chem. 1982, 47, 2697.

7. Kondo, K.; Sekimoto, E.; Miki, K.; Murakami, Y. J. Chem. Soc., Perkin Trans. 1 1998, 2973.
8. (a) Kim, T. H.; Lee, M.; Lee, G.-J.; Kim, J. N. Tetrahedron 2001, 57, 7137. (b) Lee, G.-J.; Kim, J. N.; Kim, T. H. Bull. Korean Chem. Soc. 2002, 23, 19.

9. A related 2-phenylamino-2-oxazoline was previously used as a simple leaving group in the aminolysis of $\mathrm{N}$-acyl-2-phenyliminooxazolidine, see: (a) Ganboa, I.; Palomo, C. Bull. Soc. Chim. Fr. 1982, 2, 167. (b) Lee, G.-J.; Kim, T. H.; Kim, J. N.; Lee, U. Tetrahedron: Asymmetry 2002, 13, 9.

10. (a) Mc. Arnett, E.; Miller, J. G.; Day, A. R. J. Am. Chem. Soc. 1950, 72, 5635. (b) Mc. Arnett, E.; Miller, J. G.; Day, A. R. J. Am. Chem. Soc. 1951, 73, 5393.

11. For benzyl $N$-benzylcarbamate 3a, see: Keck, G. E.; Wager, T. T.; McHardy, S. F. Tetrahedron 1999, 55, 11755.

12. For benzyl $N$-benzyl- $N$-methylcarbamate $\mathbf{3 b}$, benzyl $N$-(1phenylethyl) carbamate 3c, $N$-benzyloxycarbonyl- $N$ '-propylethylenediamine 3e, and 1-benzyloxycarbonyl-3-methylpiperazine $\mathbf{3 g}$, see: Kondo, K.; Sekimoto, E.; Nakao, J.; Murakami, Y. Tetrahedron 2000, 56, 5843.

13. For Benzyl $N$-(2-Hydroxyethyl) carbamate $\mathbf{3 h}$, see: (a) Lee, J. H.; Kim, J. D. Bull. Korean Chem. Soc. 1997, 18, 442. (b) Miller, D. J.; Bashir-Uddin Surfraz, M.; Akhtar, M.; Gani, D.; Allemann, R. K. Org. Biomol. Chem. 2004, $2,671$. 